\title{
The chiggers (Acari: Trombiculidae) on wild birds in Honduras
}

\author{
Stanislav Kalúz ${ }^{1}$, Ivan Literák ${ }^{2}$ and Stanislav Kolenčík ${ }^{2}$ \\ ${ }^{1}$ Institute of Zoology, Slovak Academy of Sciences, Bratislava, Slovakia; \\ ${ }^{2}$ Department of Biology and Wildlife Diseases, Faculty of Veterinary Hygiene and Ecology, University of Veterinary \\ and Pharmaceutical Sciences Brno, Brno, Czech Republic
}

\begin{abstract}
The chiggers (Acari: Trombiculidae) Blankaartia sinnamaryi (Floch et Fauran, 1956), Parasecia soucouyanti (Brennan et Yunker, 1966), Eutrombicula lipovskyana (Wolfenbarger, 1952) and Neoschoengastia dalmati Brennan, 1951 were found in Honduras on a total of twelve bird species. Parasecia soucouyanti was recorded parasitising birds for the first time. All these mites are here reported from Honduras for the first time.
\end{abstract}

Keywords: Blankaartia, Eutrombicula, mites, Neoschoengastia, Parasecia, Prostigmata

The larvae of mites of the family Trombiculidae (Acari), chiggers, are relatively well-studied parasites infesting a wide range of vertebrate hosts, including birds (Krantz and Walter 2009). Nearctic and Neotropical chiggers have been the subject of many studies in USA, Mexico, Guatemala, Costa Rica, Panama, Trinidad, Venezuela, Brazil and Chile (Loomis 1956, Brennan and Dalmat 1960, Brennan and Jones 1960, Loomis and Crossley 1963, Brennan and Yunker 1966, Loomis 1969, Arnold 1970, Brennan and Reed 1974, 1975, Dohany and Cromroy 1976, Rohani and Cromroy 1979, Bennett and Loomis 1980, Hoffmann 1990, Walters et al. 2011, Stekol'nikov and GonzálezAcuňa 2015, Bassini-Silva et al. 2017). Very little information on chiggers and their hosts has come from Honduras. The only data appear in a distribution map showing that chiggers of the genus Eutrombicula Ewing, 1938 and the Eutrombicula batatas (Linnaeus, 1758) species group occur in Honduras (Loomis and Wrenn 1984).

The subject of this study is to present new records of chiggers found on wild birds in Honduras. It follows on from our previous study on this topic from nearby Costa Rica (Stekol'nikov et al. 2007).

The field collection of chigger mites was run simultaneously with the investigation of ticks in Honduras during 2014 (Nováková et al. 2015). Chiggers from wild birds were collected at the Centro de Investigación y Jardín Botánico, Lancetilla, Tela, Atlantida, Honduras. This location lies in lowlands close to the Caribbean coast $\left(15^{\circ} 44^{\prime} \mathrm{N} ; 87^{\circ} 27^{\prime} \mathrm{W}\right.$, $30 \mathrm{~m}$ a.s.l.) and is surrounded by an area composed of virgin broadleaf forest and secondary forest. Collections were undertaken also on Utila Island, a small Caribbean island $33 \mathrm{~km}$ from the mainland of Honduras $\left(16^{\circ} 06^{\prime} \mathrm{N}\right.$; $86^{\circ} 54^{\prime} \mathrm{W}, 25 \mathrm{~m}$ a.s.1.) and characterised by mangrove forest, wetlands, remnants of broadleaf forest, and pastures.

Birds were trapped using ornithological mist nets and examined visually for the presence of chiggers. Trapping was from 10 to 19 August 2014 on the mainland and from 21 to 30 August 2014 on the island. Each bird was identified in accordance with Howell and Webb (1995) and Garrigues and Dean (2007). Bird scientific names follow the checklist of Clements et al. (2016). For a list of all birds examined simultaneously for ticks and trombiculid mites, see Nováková et al. (2015). Birds were released back to the wild after their examination.

The mites attached to the skin of birds were collected during naked-eye examination using tweezers and then preserved in $96 \%$ ethyl-alcohol. All mites collected were permanently mounted on slides using Swan's mounting medium (Swan 1936) and observed under a light microscope. Chiggers were identified based on their morphology according to Brennan (1951), Wolfenbarger (1952), Brennan and Yunker (1966), Floch and Fauran (1956), Goff (1992) and Stekol'nikov et al. (2007). All measurements are in micrometres. Examined mites (equally shared) will be deposited in the National Museum of Natural History, Washington, USA, Field Museum of Natural History, Chicago, USA and Slovak National Museum, Bratislava, Slovakia.

A total of 280 birds in 52 species were examined. Birds of 12 species were infested with four chigger species. At Lancetilla (L), chiggers were found on 11 of 177 birds $(6 \%$ prevalence); on Utila (U), they were found on 5 of 103 birds (5\% prevalence). Prevalence in the following species entries is expressed as number of hosts infested/number of

Address for correspondence: I. Literák, Department of Biology and Wildlife Diseases, Faculty of Veterinary Hygiene and Ecology, University of Veterinary and Pharmaceutical Sciences Brno, Palackého 1946/1, 61242 Brno, Czech Republic. Phone +420 541562630 ; Fax: +420 541 562 631; E-mail: literaki@vfu.cz 
hosts examined), while, when not self-evident, abundance is expressed as number of chiggers/host individual.

\section{Neoschoengastia dalmati Brennan, 1951}

Material examined (prevalence): three larvae, from Coraciiformes, Momotidae: Momotus lessonii Lesson (L: $1 / 1)$.

R e mark s: Neoschoengastia dalmati was first found on Momotus lessonii in Guatemala (Brennan 1951). Specimens of $N$. dalmati were recorded from two Momotus sp., while one individual was taken from Reithrodontomys sp. (Rodentia: Cricetidae) in Mexico (Brennan and Dalmat 1960). In Honduras, which neighbours Guatemala, $N$. dalmati was found for the first time.

\section{Blankaartia sinnamaryi (Floch et Fauran, 1956)}

Material examined (prevalence): 21 larvae, from Coraciiformes, Momotidae: Momotus lessonii (L: 1/1), Passeriformes, Tyrannidae: Attila spadiceus (Gmelin) (L: 1/2), Troglodytidae: Pheugopedius maculipectus (Lafresnaye) (L: 2/5), Henicorhina leucosticta (Cabanis) (L: 1/3), Polioptilidae: Ramphocaenus melanurus Vieillot (L: 1/1), Turdidae: Turdus grayi Bonaparte (L: 2/15), Parulidae: Helmitheros vermivorum (Gmelin) (U: 1/9). The 21 chiggers were distributed on individual host birds as follows: $M$. lessonii (7 larvae on 1 bird), A. spadiceus (2 larvae on 1 bird), P. maculipectus (2 and 1 larvae on 2 birds), H. leucosticta (2 larvae on 1 bird), R. melanurus (4 larvae on 1 bird), T. grayi (1 and 1 larva on 2 birds), $H$. vermivorum (1 larva on 1 bird).

$\mathrm{R} \mathrm{e} \mathrm{m} \mathrm{a} \mathrm{r} \mathrm{k} \mathrm{s:} \mathrm{This} \mathrm{chigger} \mathrm{has} \mathrm{been} \mathrm{recorded} \mathrm{in} \mathrm{widely} \mathrm{distribut-}$ ed area from the southern USA (Texas - Brennan 1965; Florida - Spalding et al. 1997) to Brazil (there B. sinnamaryi has been found parasitising birds, bats, lizards and rodents - Bassini-Silva et al. 2017) and including Costa Rica (Arnold 1970, Stekol'nikov et al. 2007), Cuba (Daniel and Stekol'nikov 2003), French Guiana (Floch and Fauran 1956), Honduras (this paper), Jamaica (Brennan 1953), Panama (Brennan and Jones 1961a, Brennan and Yunker 1966), Peru (Brennan and Jones 1961b), Suriname (Brennan and van Bronswijk 1975) and Trinidad (Brennan and Jones 1960). Brennan and Jones (1960) state this species parasitising six bird orders including six families, 13 genera and 21 species, the most numerous in the order Passeriformes (15 bird species). Bassini-Silva et al. (2017) found B. sinnamaryi on birds of two orders, three families, six genera with seven species and Walters et al. (2011) observed B. sinnamaryi parasitising three bird species belonging to three orders. It also infects the bat Phyllostomus hastatus (Pallas) (Chiroptera: Phyllostomidae), 21 bird species of more orders (Brennan and Yunker 1966) and one species of reptiles (Brennan and Jones 1960). Blankaartia sinnamaryi was reported also from the Falconiformes and Strigiformes (Brennan and Yunker 1966). This is the first report of B. sinnamaryi in Honduras. Of the seven bird species parasitised there, M. lessonii, P. maculipectus, R. melanurus, T. grayi and $H$. vermivorum are new host records.

\section{Parasecia soucouyanti (Brennan et Yunker, 1966)}

Material examined (prevalence): 16 larvae, from Piciformes, Picidae: Centurus aurifrons (Wagler) (L: 1/2, U: 2/10), Passeriformes, Furnariidae: Xiphorhynchus guttatus (Lichtenstein) (L: 1/7). The 16 larvae were distributed on indi- viduals of the birds as follows: Centurus aurifrons (1,2 and 11 larvae on 3 birds), $X$. guttatus (2 larvae on 1 bird).

R e m a rks: The original description of $P$. soucouyanti reported the bat Sturnira ludovici Anthony (Chiroptera: Phyllostomidae) as the type host and also recorded it from the bat Myotis sp. (Vespertilionidae) in Panama (Brennan and Yunker 1966). An additional host is the rodent Rhipidomys venustus Thomas in Venezuela (Brennan and Reed 1975). We enlarged the distribution area of $P$. soucouyanti to include Honduras and also recorded it from birds for the first time.

\section{Eutrombicula lipovskyana (Wolfenbarger, 1952)}

Material examined (prevalence): three larvae, from Passeriformes, Vireonidae: Vireo olivaceus (Linnaeus) (U: 1/12), Parulidae: Seiurus aurocapilla (Linnaeus) (U: 1/10), Geothlypis formosa (Wilson) (L: 1/2). Each parasitised bird carried one larva.

R e m a r k s: This chigger is known to occur in midwestern and southern USA (Kansas, Oklahoma, Tennessee, Mississippi, Louisiana and Arkansas) and to parasitise amphibians (two species in two genera), turtles (one species), lizards (two families with two species in two genera), snakes (two families with two species in two genera), birds (two orders, Ralliformes with one species and Passeriformes with 20 species in 19 genera; Wolfenbarger 1952, Walters et al. 2011). It has also been recorded from Panama and Cuba (Daniel and Stekol'nikov 2004). We report E. lipovskyana for the first time from Honduras and also from the three species on which it was found. All the host species breed in North America and winter in Central America and South America. In September, when we examined birds in Honduras, these host species were in their post-breeding migration and beginning to appear in their wintering grounds (Howell and Webb 1995, Garrigues and Dean 2007). We suppose that migrating birds substantially contribute to the distribution of E. lipovskyana in the territory of its occurrence. Brennan and Yunker (1966) noted this taxon (as form of Eutrombicula alfreddugesi [Oudemans]) from the highlands of Chiriqui in Panama, suggesting the species may naturally occur in Central America. Dietsch (2005) brings the study on chiggers parasitising migrating birds in Chiapas (Mexico). The author did not specify the species of chiggers, but more than 60 bird species were studied - nearly all of them (including all the above mentioned bird species reported from Honduras) were the hosts of larvae possibly of E. lipovskyana. The importance of birds as hosts of chiggers is also shown in the paper of Philips (2000) where the author presented 28 raptors as hosts of 25 different chigger species including $E$. lipovskyana. The chigger E. lipovskyana has been known from numerous hosts (various groups of vertebrates) and over a wide geographic range. Among the bird species studied by us $V$. olivaceus is known as a host of another chigger $E$. alfreddugesi from the Caribbean region (Walters et al. 2011). The information stated above indicates that E. lipovskyana is a non-specific parasite; the larvae show a wide ecological and geographical plasticity.

With respect to the relationships between chiggers and their bird hosts, some common aspects arise:

(1) All bird species studied by us have a large geographic distribution (Howell and Webb 1995, Garrigues and Dean 2007): M. lessonii from southern Mexico to southwestern Panama (Stiles 2009); A. spadiceus from north-western 
Mexico to western Ecuador, Bolivia, southeastern Brazil to Trinidad; P. maculipectus from Mexico, Belize, Costa Rica, El Salvador, Guatemala, Honduras to Nicaragua; $H$. leucosticta from central Mexico to northeastern Peru and Surinam; $R$. melanurus from Mexico south to Brazil, eastern Venezuela, Colombia and Trinidad; T. grayi from South Texas, Mexico to northern Colombia; $H$. vermivorum from eastern United States, Mexico, Central America to Greater Antilles; S. aurocapilla from eastern North America, Florida, Central America, many Caribbean islands to northern Venezuela; C. aurifrons from South United States (NW Texas, SW Oklahoma), Mexico, El Salvador, southwestern Honduras to northcentral Nicaragua; G. formosa from central and eastern United States (often ranging as far north as Wisconsin to Pennsylvania) to the Yucatán Peninsula and from many islands of the Caribbean to North Venezuela; $V$. olivaceus from the United States, many Caribbean islands, Colombia, Chile, French Guiana to Uruguay; X. guttatus from eastern Colombia through northern Brazil, southern and eastern Venezuela to the Guianas (French Guiana, Guyana, Suriname).

(2) Some of these birds migrate through Honduras or winter in this area (Dietsch 2005).
(3) They mostly forage on the ground or in low vegetation (Garrigues and Dean 2007).

(4) Their nests are built on the ground, in bank tunnels or in low vegetation. These factors can facilitate the contact between the chiggers and bird hosts dwelling on the soil surface or inhabiting on low vegetation. The territory of distribution of $P$. soucouyanti, B. sinnamaryi and probably also E. lipovskyana follows that of the majority of host birds mentioned above. Moreover, these chiggers are able to parasitise a wide spectrum of hosts. We suppose that these chigger species can be associated mainly with the birds that are characterised by the above mentioned factors. However, not enough information on the hosts or distribution of $N$. dalmati is available to allow any generalisations to be made.

Acknowledgements. We thank Alberto Andres Velasques Castillo and Miroslav Valan for their co-operation in the field. The field study was permitted by the Instituto Nacional de Conservación y Desarrolo Forestal, Áreas Protegidas y Vida Silvestre, Gobierno de la República de Honduras (DE-MP-063-2014). The study was supported partially by the Slovak Scientific Grant Agency VEGA (grant 2/0139/17). We are grateful to anonymous reviewers for their comments and valuable advice.

\section{REFERENCES}

Arnold K.A. 1970: Notes on avian ectoparasites from Costa Rica. I. Acarina and Diptera. Rev. Biol. Trop. 16: 259-265.

Bassini-Silva R., Jacinavicius F. C., Mendoza-Roldan J. A., Daemon E., Barros-Battesti D. M. 2017: Description of Blankaartia shatrovi n. sp. (Acari: Trombiculidae) from Brazil. J. Med. Entomol. 54: 82-90.

Bennett S.G., Loomis R.B. 1980: The tropical pest chigger Eutrombicula batatas (Acarina: Trombiculidae) in Arizona and California, USA. J. Med. Entomol. 17: 286.

Brennan J.M. 1951: Two new species of Neoschongastia with a key to the species of the world (Acarina: Trombiculidae). J. Parasitol. 37: 577-582.

BREnNAN J.M. 1953: A note on the chiggers of Jamaica (Acarina: Trombiculidae). J. Parasitol. 39: 292-295.

BREnNAN J.M. 1965. Two new species and other records of chiggers from Texas (Acarina: Trombiculidae). Acarologia 7: 79-83.

Brennan J.M., van BronswiJk J.E.M.H. 1975: Parasitic mites of Surinam. XXI. New record of Surinam and certain French Guiana chiggers with the description of a new species of Loomisia Brennan \& Reed, 1972 (Acarina, Trombiculidae). J. Med. Entomol. 12: 243-249.

Brennan J.M., Dalmat H.C. 1960: Chiggers of Guatemala (Acarina: Trombiculidae). Ann. Entomol. Soc. Am. 53: 183-191.

Brennan J.M., Jones E.K. 1960: Chiggers of Trinidad B.W.I. (Acarina: Trombiculidae). Acarologia 2: 493-540.

Brennan J.M., Jones E.K. 1961a: New genera and species of chiggers from Panama (Acarina: Trombiculidae). J. Parasitol. 47: $105-124$.

Brennan J.M., Jones E.K. 1961b: Chiggers of Peru (Acarina: Trombiculidae). Acarologia 3: 172-205.

Brennan J.M., Reed J.T. 1974: The genus Eutrombicula in Venezuela (Acari: Trombiculidae). J. Parasitol. 60: 699-711.

Brennan J.M., ReED J.T. 1975: A list of Venezuela chiggers, particularly of small mammalian hosts (Acarina: Trombiculidae). Brigh. Young Univ. Sci. Bull., Biol. Ser. 20: 45-75.

Brennan J.M., Yunker C.E. 1966: The chiggers of Panama (Acarina: Trombiculidae). In: R.L. Wenzel and V.J. Tipton (Eds.), Ec- toparasites of Panama. Field Museum of Natural History, Chicago, pp. 221-266.

Clements J.F., Schulenberg T.S., Iliff J., Roberson D., Fredericks T.A., Sullivan B.L., Wood C.L. 2016: The eBird/Clements checklist of birds of the world: v2016. www. birds.cornell.edu/clementschecklist/download/, 4/2017.

Daniel M., Stekolnikov, A.A. 2003: Chigger mites (Acari: Trombiculidae) new to the fauna of Cuba with description of two new species. Folia Parasitol. 50: 143-150.

Daniel M., Stekolnikov, A.A. 2004: Chigger mites of the genus Eutrombicula Ewing, 1938 (Acari: Trombiculidae) from Cuba with description of three new species. Folia Parasitol. 51: $359-366$.

Dietsch T.V. 2005: A comparison of ectoparasite infestation by chigger mite larvae (Acarina: Trombiculidae) on resident and migratory birds in Chiapas, Mexico illustrating a rapid visual assessment protocol. In: C. J. Ralph; T. D. Rich (Eds.) Bird Conservation Implementation and Integration in the Americas: Proceedings of the Third International Partners in Flight Conference. 20-24 March 2002; Asilomar, California, Volume 1 and 2. USDA Forest Service Gen. Tech. Rep. PSW-GTR-191, pp. 1129-1137.

Dohany A.L., Cromroy H.L. 1976: New records of chiggers (Acarina: Trombiculidae) from Florida. Florida Entomologist 59: 183-190.

Floch H., Fauran P. 1956: Sur deux espèces du genre Trombicula (Acariens, Trombiculidae) nouvelles pour la faune de la Guyane Française: Trombicula alfreddugesi (Oudemans, 1910) et Trombicula sinnamaryi n. sp. Arch. Inst. Pasteur Guyane Fr. 17: 1-7.

Garrigues R., Dean R. 2007. Birds of Costa Rica. Christopher Helm Publishers Ltd., London, 387 pp.

Goff L. M.1992: The genus Parasecia (Acari: Trombiculidae), with the description of a new species from Mexico. J. Med. Entomol. 29: 965-967.

Hoffmann A.1990: Los Trombiculidos de Mexico (Acarida: Trombiculidae): Parte Taxonómica. Publicaciones Especiales del Instituto de Biologia, Universidad Nacional Autónoma de México, Facultad de Ciencias, México, D.F., México, 276 pp. 
Howell S.N.G., WebB S. 1995: A Guide to the Birds of Mexico and Northern Central America. Oxford University Press, Oxford, $851 \mathrm{pp}$.

Krantz G.W., Walter D.E. 2009 (Eds.): A Manual of Acarology. Texas Tech University Press, Lubbock, 807 pp.

Loomis R. B. 1956: The chigger mites of Kansas (Acarina: Trombiculidae). Univ. Kansas Sci. Bull. 37: 1195-1443.

Loomis R.B. 1969: Chiggers (Acarina, Trombiculidae) from vertebrates of the Yucatan Peninsula, Mexico. Univ. Kansas, Mus. Nat. History, Misc. Publ. 50: 1-22.

Loomis R.B., Crossley D.A. JR. 1963: New species and new records of chiggers (Acarina: Trombiculidae) from Texas. Acarologia 5: 371-383.

Loomis R.B., WrenN W.J. 1984: Systematics of the pest chigger genus Eutrombicula (Acari: Trombiculidae). In: D.A. Griffiths, C.E. Bowman (Eds.), Acarology 6, Vol. 1. Ellis Horwood Limited, Chichester, pp. 152-159.

Nováková M., Literák I., Chevez L.F., Martins T.F., OgrzeWALSKA M., LABRUNA M.B. 2015: Rickettsial infections in ticks from reptiles, birds and humans in Honduras. Ticks Tickborne Dis. 6: 737-742.

Philips J.R. 2000: A review and checklist of the parasitic mites (Acarina) of the Falconiformes and Strigiformes. J. Raptor Res. 34: $210-231$.

Rohani I.B., Cromroy H.L. 1979: Taxonomy and distribution of chiggers (Acarina: Trombiculidae) in northcentral Florida. Fla. Entomol. 62: 363-376.
Spalding M.G., Wrenn W.J., Schwikert S.T., Schmidt J.A. 1997. Dermatitis in young Florida sandhill cranes (Grus canadensis pratensis) due to infestation by the chigger, Blankaartia sinnamaryi. J. Parasitol. 83: 768-771.

Stekolnikov A., LiterÁK I., ČAPeK M., HavlíčeK M. 2007: Chigger mites (Acari: Trombiculidae) from wild birds in Costa Rica, with a description of three new species. Folia Parasitol. 54: 59-67.

Stekolnikov A.A., GonzÁlez-Acuña D. 2015: A review of Chilean chiggers (Acari: Trombiculidae), with the description of a new genus and ten new species. Zootaxa 3964: 1-43.

Stiles F.G. 2009: A review of the genus Momotus (Coraciiformes: Momotidae) in northern South America and adjacent areas. Ornitología Colombiana 8: 29-75.

SWAN D.C. 1936: Berlese's fluid: remarks upon its preparation and use as a mounting medium. Bull. Entomol. Res. 27: 389-391.

Walters B.L., Whitaker J.O. JR., Gikas N.S., Wrenn W.J. 2011: Host and Distribution Lists of Chiggers (Trombiculidae and Leeuwenhoekiidae), of North American Wild Vertebrates North of Mexico. Faculty Publications from the Harold W. Manter Laboratory of Parasitology. Paper 697: 183 pp.

Wolfenbarger K.A. 1952. Systematic and biological studies on North American chiggers of the genus Trombicula subgenus Eutrombicula (Acarina, Trombiculidae). Ann. Entomol. Soc. Am. 45: 645-677.

Cite this article as: Kalúz S., Literák I., Kolenčík S. 2018: The chiggers (Acari: Trombiculidae) on wild birds in Honduras. Folia Parasitol. 65: 017. 